\title{
Feasibility to realize zero medical burden for pulmonary tuberculosis outpatients through China's new rural cooperative medical system
}

Xu Zuhui, Bai Liqiong, Tang Yi, Gong Dehua, Yirui Zhang

Department of TB Control, TB Control institution of Hunan Province, Hunan, China

Address for the Correspondence: Prof. Bai Liqiong, TB Control Institution of Hunan Province, Hunan, China. E-mail: liqong99@126.com

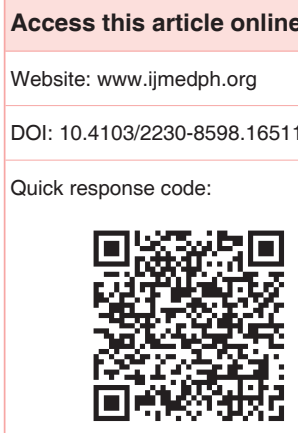

Objective: To explore the feasibility of case-based payment (zero medical expense) for pulmonary tuberculosis (PTB) outpatients through the new rural cooperative medical system (NRCMS) in Hunan province. Materials and Methods: Cross-section and qualitative study were applied. All 131 counties of Hunan province were investigated to identify the current situation of medical security in tuberculosis (TB) patients by questionnaire and telephone interview. Thirty-six staff of nine pilot counties, which already implemented case-based payment were interviewed on their opinions of case-based payment, interviewees were from health bureau, NRCMS sectors and centers for disease control and prevention (CDC) of each county. Results: Outpatient PTB treatment for rural patients was covered by NRCMS in 118 of all 131 counties. Reimbursement models consist of proportional reimbursement, fixed amount reimbursement, and case-based payment. However, the proportion of proportional reimbursement has a range of $30-80 \%$, the payment of amount reimbursement varies from 200 to $1500 \mathrm{RMB}$ Yuan/case. Patients covered by proportional reimbursement and fixed amount reimbursement need to pay the medical expense of 588 Yuan/case and 463 Yuan/case respectively, comparing zero expenditure for patients of case-based payment. NRCMS need input about 17.8 million Yuan more per year to reimburse all rural PTB outpatients' medical expenses, which only accounted for $0.12 \%$ of total NRCMS fund. In those counties, which already implemented case-based payment policy, the number of patients visited CDCs has increased dramatically, follow-up and treatment compliance improved obviously as well. Conclusion: Zero outpatient medical burden for rural TB patients is feasible and realizable through case-based payment under China's NRCMS.

Key words: Case-based payment, feasibility, outpatient, tuberculosis, zero burden

\section{INTRODUCTION}

China is one of the 22 high tuberculosis (TB) burden counties. Although China has free TB diagnosis and treatment policy, most patients have to pay additional diagnosis and treatment expenses (such as liver and kidney function test, liver protect medicine), which may lead to treatment interruption due to patients' low affordability. ${ }^{[1,2]}$ Therefore, Hunan province launched a so-called case-based payment pilot project in fourteen counties successively from 2009 to 2012 to cover all patient expenses through China's new rural cooperative medical system (NRCMS). Under this pilot project, patients would not pay any medical fee in the whole treatment course. This research is to explore its feasibility.

\section{MATERIALS AND METHODS}

\section{Research methods \\ Both cross-section study and qualitative study were applied.}

The self-designed questionnaires were filled through E-mail in all Hunan's 131 counties about how outpatient pulmonary TB (PTB) was reimbursed by NRCMS in 2012. Questions included "if outpatient PTB was covered by NRCMS," "the model of outpatient TB reimburse," "how much (amount and percentage) one patient can be reimbursed after a full course treatment” and other relevant questions, 
the relevant government materials were also collected as supporting document. All 131 questionnaires were replied, those uncompleted or incorrect were completed and verified through a telephone interview and official documents. All the questionnaires were entered in Microsoft office excel for analysis to identify the current status of PTB reimbursement in NRCMS, and to figure out the extra funding needed to realize all rural patients' fully free treatment.

From April to October in 2012, nine of fourteen case-based payment pilot counties were randomly selected to in-depth interview, one NRCMS sector chief and one director of local health bureau (normally NRCMS sector belong to local health bureau), one director and one TB special doctors from centers for disease control and prevention (CDC) in every county, that is, total 36 persons were interviewed. The interview outlines consisted of "how case-based payment affected patient case funding and management," "the reimbursement procedure," "opinions and suggestions about reimbursement," et al. all the interview were recorded in both hard paper and recorder. Aftermath the materials were coded, sorted and numbered. Descriptive and explanatory analysis was done based on these materials.

To better understand the influencing of case-based payment on PTB case funding, in the six pilot counties, which had conducted pilot before January 2012, the number of first visit patients (with suspected TB symptom) of 6 months before and after case-based payment implemented was collected and compared. These data were collected from Chinese internet-based TB management information system and was verified by local CDCs.

\section{Related definitions and clarification}

There are three main models in terms of NRCMS reimbursement: Proportional reimbursement, fixed amount reimbursement, and case-based payment. Proportional reimbursement is to reimburse a fixed percentage of the medical expenses within a maximum amount. Fixed amount reimbursement means set an upper limit of refund fee for one kind of disease, and pay in full of patients' cost within this limit. Patients pay the extra cost if the total medical cost overpasses the upper limit. Case-based payment means all patients fee is to be reimbursed no matter how much is the actual expense, after the fixed amount of fee for a certain disease is set.

The three models of reimbursement were similar to reported models in China's other area ${ }^{[3]}$ and all selected counties were following the national TB control program guideline in terms of TB diagnostic and therapeutic services.

In the 14 case-based payment pilot counties, NRCMS secretors would pay all medical expenses to CDCs, which were responsible to offer full free and quality treatment (6-8 months) for PTB outpatients. In practice, patients' costs of 10 counties automatically paid by NRCMS during their treatment, the only thing they need to do is to show their NRCMS paper to CDCs, while in the other 4 counties, patients have to pay the costs as deposit and to reclaim after finishing treatment course, which cause inconvenience, but finally they still can have the zero payment.

\section{RESULTS}

\section{The reimbursement of new rural cooperative medical system for outpatients tuberculosis treatment}

Out of 131 counties in Hunan province, outpatients TB treatment were coved by NRCMS in $118(90.1 \%)$ counties, whereas the other $13(9.9 \%)$ counties have not refunded outpatients TB treatment yet.

Thirty-two out of $118(27.1 \%)$ counties undertook proportional reimbursement. The proportion was between $30 \%$ and $80 \%$, with the average of $50 \%$. The average upper limit was 800 Yuan/case (200-6000 Yuan/case). Seventy-two (61.0\%) counties undertook fixed amount reimbursement, the average amount was 500 Yuan/case (200-1500 Yuan/case), among which reimburse amount of 14 counties was above 800 Yuan/case (provincial suggesting minimum reimbursement fee). Case-based payment was implemented in 14 counties, accounting 11.9\% (14/118) of all counties with NRCMS. The average fixed reimbursement was 925 Yuan/case, varied from 600/case to 1300 Yuan/case.

The three models of reimbursement counties had comparable economic development [Table 1]. However, the rich area shared higher reimbursement standard in all three models, 13 of 19 counties were above average reimbursement level from the developed area, comparing only 11 of 38 counties above average level from

\begin{tabular}{|c|c|c|c|c|c|c|}
\hline \multirow[t]{2}{*}{ Categories } & \multicolumn{2}{|c|}{$\begin{array}{l}\text { Proportional } \\
\text { reimbursement }\end{array}$} & \multicolumn{2}{|c|}{ Fixed amount reimbursement } & \multicolumn{2}{|c|}{$\begin{array}{c}\text { Case-based } \\
\text { payment }\end{array}$} \\
\hline & $\begin{array}{c}\text { Number } \\
\text { of counties }\end{array}$ & $\begin{array}{l}\text { Total number of TB } \\
\text { patients in } 2012 \\
\text { (proportion) (\%) }\end{array}$ & $\begin{array}{c}\text { Number } \\
\text { of counties }\end{array}$ & $\begin{array}{l}\text { Total number of TB } \\
\text { patients in } 2012 \\
\text { (proportion) (\%) }\end{array}$ & $\begin{array}{l}\text { Number } \\
\text { of counties }\end{array}$ & $\begin{array}{l}\text { Total number of TB } \\
\text { patients in } 2012 \\
\text { (proportion) (\%) }\end{array}$ \\
\hline Developed area & 4 & $1215(9.2)$ & 13 & $6044(17.6)$ & 2 & $1438(16.7)$ \\
\hline $\begin{array}{l}\text { Middle-developed } \\
\text { area }\end{array}$ & 18 & $7869(59.4)$ & 35 & $16,666(48.5)$ & 8 & $5177(60.2)$ \\
\hline $\begin{array}{l}\text { Underdeveloped } \\
\text { area }\end{array}$ & 10 & $4162(31.4)$ & 24 & $11,687(33.9)$ & 4 & $1982(23.0)$ \\
\hline Total & 32 & $13,246(100)$ & 72 & $34,397(100)$ & 14 & $8597(100)$ \\
\hline
\end{tabular}


undeveloped area. The two counties had least case-based payment (600 Yuan/case) mainly were due to poor social-economic status.

Bai's rearch ${ }^{[4]}$ showed every rural TB case in Hunan province need to pay 1015 Yuan for outpatient treatment, according to this standard, patients covered by proportional reimbursement and fixed amount reimbursement need to pay medical expense of 588 Yuan/case and 463 Yuan/case respectively, comparing zero expenditure for patients of case-based payment. NRCMS need to input about 42.2 million Yuan to meet the demand for outpatient for all active PTB outpatient treatment, which account for $0.31 \%$ of provincial NRCMS' fund pool (around 13.4 billion Yuan). ${ }^{[5]}$ Moreover, the fund gap to cover all outpatient expenses for all rural TB patients were 17.8 million, still only $0.12 \%$ of NRCMS' total fund [Table 2]. ${ }^{[6]}$

\section{Services utilization of outpatient care}

After the case-based payment was implemented, the number of first visit patients (visiting CDC for suspected TB symptoms) in five of six counties had increased [Chart 1], the average increasing rate was $12.8 \%$. At the same time, the number of total TB patients only raised 3.3\% which showed big attraction for patients to seek outpatient treatment in CDCs. As one CDC staff said: After casebased payment had implemented, the number of patients visiting CDC increased sharply, which improved obviously TB case finding. In addition, TB patients would come back to CDC for re-examine proactively without telephone follow-up. Therefore, the treatment compliance became much better.

\section{The payment of new rural cooperative medical system}

All interviewees from health bureau had shown concern on the influx of TB patients onto CDCs and over-expenditure of NRCMS fund before the pilot project implemented, but the results had swept away their worry. The costs of TB outpatients did not increase sharply (only county had significant increasing as its upper limit reimbursement for TB increased from 300 Yuan/case to 1200 Yuan/case after the pilot). Moreover, the expenditure on TB only accounted for a minimal part of their total fund. As one NRCMS staff said: The main concerns now are how to assure the fund to be used properly instead of worrying about overspending. More policy support and normative documents are needed to improve the reimbursement process and to benefit patients' healthiness.

\section{DISCUSSION}

\section{Zero medical burden for tuberculosis outpatients can be realized through case-based payment, utilizing China's new rural cooperative medical system}

China has a free treatment policy for PTB, including free antiTB drugs, 3 times free smear sputum tests and twice free chest examinations. ${ }^{[7]}$ However, most patients have to pay for auxiliary examination and treatment, which may cost few hundred to thousand Yuan. ${ }^{[4]}$ As over $70 \%$ of TB patients are from the rural area, whose poor social-economic status ${ }^{[8]}$ and low affordability may lead to interruption of treatment. ${ }^{[9,10]}$ With the implementing of NRCMS policy, the rural population will have a higher level of health insurance, which makes zero medical burden for TB outpatients possible.

Tuberculosis has been an important disease leading catastrophic

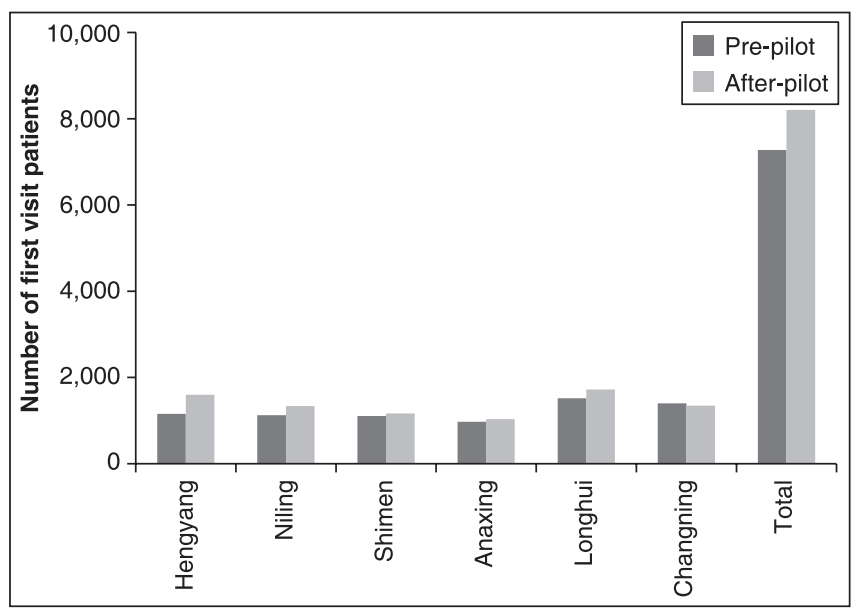

Chart 1: The number of first visit patients in centers for disease control and preventions before (from January to June in 2011) and after (from January to June in 2012) case-based payment

\begin{tabular}{|c|c|c|c|c|c|}
\hline $\begin{array}{l}\text { Reimbursement } \\
\text { models }\end{array}$ & $\begin{array}{l}\text { Number } \\
\text { of counties }\end{array}$ & Mean/median & $\begin{array}{c}\text { Number of rural TB } \\
\text { patients between July } \\
2011 \text { and June } 2012^{\mathrm{a}}\end{array}$ & $\begin{array}{c}\text { Estimated outpatient } \\
\text { treatment expense } \\
\text { per case }(\text { Yuan) }\end{array}$ & $\begin{array}{l}\text { Fund gap to cover all } \\
\text { outpatient expenses } \\
\text { (million Yuan) }\end{array}$ \\
\hline $\begin{array}{l}\text { Proportional } \\
\text { reimbursement }\end{array}$ & 32 & $\begin{array}{l}50 \% \text { reimbursement, upper limit } \\
800 \text { Yuan/case }\end{array}$ & 9921 & 588 & 5.8 \\
\hline $\begin{array}{l}\text { Fixed amount } \\
\text { reimbursement }\end{array}$ & 72 & $500(200-1500)$ Yuan/case & 25,744 & 463 & 11.9 \\
\hline $\begin{array}{l}\text { Case-based } \\
\text { payment }\end{array}$ & 14 & 925 (600-1300) Yuan/case & 5961 & 0 & - \\
\hline Total & 118 & - & 41,626 & & 17.8 \\
\hline
\end{tabular}

a Number of rural pulmonary TB cases $=$ Number of all pulmonary TB cases in local area $\times$ the proportion of rural cases in all cases in Hunan province $(77.0 \%[42,825 / 55,617]) \times$ the proportion of covered by NRCMS in all rural population $97.2 \% .{ }^{[6]}$ The number of pulmonary TB cases and number of rural TB cases came from Chinese internet-based TB

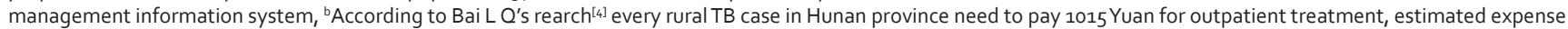
was calcuated after detucted the NRCMS reimburesment, TB = Tuberculosis, NRCMS = New rural cooperative medical scheme 
spending, Ruan et al. ${ }^{[11]}$ reported $19.6 \%$ patients from rural area occurred catastrophic spending, while hospitalized TB patients had a much more higher expenditure than outpatient patients, Zhao and $\mathrm{Li}^{[12]}$ reported $65.8 \%$ catastrophic spending rate in TB special hospital even for patients with health insurance. The implementation of case-based payment can not only increase the proportion of outpatients, but also lower medical expense and reduce the occurring of catastrophic spending. ${ }^{[13]}$

Most PTB cases just need outpatient treatment according to national TB control program guideline. ${ }^{[7]}$ However, China's casebased payment mainly target inpatients, ${ }^{[14,15]}$ moreover, Li et al. ${ }^{[3]}$ reported that $96.6 \%$ of China's counties reimburse TB inpatients, while $45.3 \%$ counties reimburse TB outpatients. Therefore, casebased payment for TB inpatients could be an adventurous step on releasing patients' medical burden. The pilot project showed patients had enjoyed full fee medial service, which not only increased TB control sectors' treatment quality, but enhanced case finding level. ${ }^{[16,17]}$ With the case-base payment benefitting more and more patients, "some urban TB patients also want to enjoy the case-based payment policy as they have to pay a lot of auxiliary treatment expenses." said by one health bureau chief. How to increase reimbursement for urban patients and those minor rural patients who are not covered by NRCMS should be our future consideration.

\section{New rural cooperative medical system sectors need to increase its investment to support case-based payment policy}

Hunan province is in the middle and is a middle-developed area of China. The levels of reimbursement for outpatient TB in NRCMS varies from county and county, and most (mainly from underdeveloped area) counties' reimbursement was lower than provincial recommending standard. However, some poor counties also have better reimbursement than rich area. Heath sectors need to do more efforts to release the burden of patients. According to the provincial suggesting reimburse standard, NRCMS need to input about 17.8 million Yuan more to meet the minimum demand for outpatient treatment for all active TB patients, which only account for $0.12 \%$ of NRCMS' total fund. And some counties $(12.4 \%)$ can realize patients' zero medical burden without any increasing. Comparatively, the fund raising of NRCMS has increased year by year, insurance fund of 2013 will increased to 340 Yuan/case from 290 Yuan/person in $2012,{ }^{[5,16,18]}$ increases by $17.2 \%$. The main thing is how to enhance our policy advocacy, to strength government commitments, and mobilize more counties to implement case-based payment.

Overall, case-based payment for outpatient TB can truly release patients' medical burden and enhance the quality of TB care. The pilot in Hunan province has proved it realizable. However, it needs fully cooperation and support of the government, NRCMS sectors and TB control sectors to implement this policy.

\section{ACKNOWLEDGMENTS}

The authors thank the World Health Organization (WHO) in Beijing and Chinese Global Fund tuberculosis program for funding.

\section{REFERENCES}

1. Du WY, Yang $\mathrm{CX}$. What to be strengthened in pulmonary TB DOT according to the causes of treatment interruption. Dis Monit Control 2010;6:355-6.

2. Liu GC, Yu RS. To indentify risk factors of treatment interruption in seventy pulmonary tuberculosis patients. Chin Health Ind 2011;9:111-2.

3. Li Y, Li X, Xie HB, Zhang H, Wang LX, Jiang SW. Analysis on the reimbursement situation of TB treatment costs in the new rural cooperative medical system. Chin J Antituberculosis 2010;32:685-9.

4. Bai LQ. Economic Burden and Impacts of Pulmonary Tuberculosis Patients in Hunan Province. [D] Changsha: Center-South University; 2009.

5. Coordination Committee of Hunan New Rural Cooperative Medical System, Notice on Increasing Fund Raising Level Per Capital of New Rural Cooperative Medical System in Hunan in 2012. Available from: http://www.hnhzyl.cn/hzyl_wz.asp?wzid=1249. [Last accessed on 2013 Jan 8].

6. Statistics Bureau of Hunan Province. Economy and Society Developing Statistics Bulletin of Hunan Province in 2011. Available from: http://www. hntj.gov.cn/tjgb/glgb/201203/t20120320_91801.htm. [Last accessed on 2012 Dec 24].

7. Xiao DL, Zhao MG, Wang Y, Wang LX, Xu SF, Wang WJ, et al. Guideline for National TB Control Program Implementation, Version of 2008. Beijing: Xiehe Medicine University Press; 2009.

8. Wang Y. Collection on the Fifth Nationwide TB Epidemiologic Survey. Beijing: Press of Military Medicine and Since; 2011. p. 3.

9. Xu B, Diwan VK, Bogg L. Access to tuberculosis care: What did chronic cough patients experience in the way of healthcare-seeking? Scand $\mathrm{J}$ Public Health 2007;35:396-402.

10. Barter DM, Agboola SO, Murray MB, Bärnighausen T. Tuberculosis and poverty: the contribution of patient costs in sub-Saharan Africa - A systematic review. BMC Public Health 2012;12:980.

11. Ruan $Y Z$, He GX, Zhang H, Jiang SW, Wang XJ, Wang LX. Analysis of the socio-economic status of 1301 tuberculosis cases. Chin J Antituberculosis 2012;34:572-5.

12. Zhao J, Li RZ. Status of the diagnosis, treatment and management of tuberculosis in TB specialized hospitals. Chin $\mathrm{J}$ Health Educ 2011;27:13-7.

13. Chen J, Zheng YH, Deng HJ, Liu YC. Catastrophic health expenditure among migrants with tuberculosis in Putuo District, Shanghai. Shanghai J Prev Med 2012;24:590-2.

14. Zhang X, Wang LS. The utilization of case-based payment in China's new rural cooperative system pilot sites.

15. Ministry of Health, Committee of Developing and Reformation. The Notice on Related Issues of Case-based Payment Reform Pilot. Available from: http://www.ndrc.gov.cn/jggl/jggs/t20110407_404333.htm. [Last accessed on 2012 Aug 8].

16. Zhang YR, Bai LQ, Gong DH, Peng GQ, Xu B, Tang Y, et al. Effects of case based payment $f$ or TB outpatient auxiliary diagnosis and treatment on TB patients detection and treatment. Chin J Antituberculosis 2011;33:666-70.

17. Liu EY, Wang XJ, Xue X, Gao MQ, Zhang LQ, Bai LQ, et al. Retrospective survey of outpatient TB service in TB institutions under Hunan casebased payment pilot project. Chin J Antituberculosis 2011;33:739-42.

18. Ministry of Health. Bulletin of Ministry of Health on National Health Work Conference. Available from: http://www.gov.cn/xwfb/2013-01/10/ content_2308947.htm. [Last accessed on 2013 Jan 8].

How to cite this article: Zuhui X, Liqiong B, Yi T, Dehua G, Zhang Y. Feasibility to realize zero medical burden for pulmonary tuberculosis outpatients through China's new rural cooperative medical system. Int J Med Public Health 2015;5:332-5.

Source of Support: Nil, Conflicts of Interest: None declared. 